Compared with patients with thyroid carcinoma, patients with CASTLE seem to have a better prognosis. However, CASTLE has a potentially invasive behavior, and invasion of neighboring cervical structures is possible. In particular, tracheal ${ }^{2}$ or laryngotracheal ${ }^{3}$ resections have been necessary to excise the lesion. The extent of this invasion may sometimes prevent a complete resection ${ }^{1}$ or require surgically challenging procedures, as in our experience. The parietal invasion can involve the muscles, connective tissue, and skin., ${ }^{4,5}$

Nodal involvement is probably a negative prognostic factor, because it has been associated with the occurrence of locoregional ${ }^{3}$ or systemic spread. ${ }^{1,2}$ Adjuvant radiotherapy is generally advocated in case of nodal metastasis. On the other hand, local recurrence is possible in the absence of nodal disease, thus suggesting a role for systematic adjuvant radiotherapy because of the radiosensitivity of this tumor. ${ }^{1}$

\section{References}

1. Luo CM, Hsueh C, Chen TM. Extrathyroid carcinoma showing thymuslike differentiation (CASTLE) tumor: a new case report and review of literature. Head Neck. 2005;27:927-33.

2. Miyauchi A, Kuma K, Matsuzuka F, Matsubayashi S, Kobayashi A, Tamai $\mathrm{H}$, et al. Intrathyroidal epithelial thymoma: an entity distinct from squamous cells carcinoma of the thyroid. World J Surg. 1985;9: $128-35$.

3. Mizukami Y, Kurumaya H, Yamada T, Minato H, Nonomura A, Noguchi M, et al. Thymic carcinoma involving the thyroid gland: report of two cases. Hum Pathol. 1995;26:576-9.

4. Bayer-Garner IB, Kozovska ME, Schwartz MR, Reed JA. Carcinoma with thymus-like differentiation arising in the dermis of the head and neck. J Cutan Pathol. 2004;31:625-9.

5. Ahuja AT, Chan ESY, Allen PW, Lau KY, King W, Metreweli C. Carcinoma showing thymic-like differentiation (CASTLE tumor). AJNR Am J Neuroradiol. 1998;19:1225-8.

\title{
A new technique for prosthetic reconstruction of the superior vena cava
}

\author{
Antonio D'Andrilli, MD, ${ }^{a}$ Anna Maria Ciccone, MD, ${ }^{a}$ Mohsen Ibrahim, MD, ${ }^{a}$ Federico Venuta, MD, \\ and Erino A. Rendina, MD, ${ }^{a}$ Rome, Italy
}

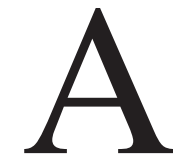

lthough the feasibility of resection and prosthetic replacement of the superior vena cava (SVC) has been largely proven, ${ }^{1}$ the type of vessel reconstruction is still an object of debate and the search for improved technical devices is currently active.

We describe a new technique for the construction of the pericardial tube that we have successfully used in 2 cases of reconstruction of the SVC.

\section{Clinical Summary}

Case 1 was a 50 -year-old man who presented with a large right pulmonary mass $(11 \mathrm{~cm}$ in diameter) invading the carina, SVC, pulmonary artery, and superior pulmonary vein. Histologic diagnosis achieved by endobronchial biopsy was mesenchymal proliferation of uncertain behavior. After laser recanalization of the right main bronchus by rigid bronchoscopy, the patient underwent op-

\footnotetext{
From the Department of Thoracic Surgery, University of Rome "La

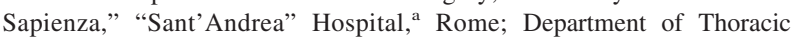
Surgery, University of Rome "La Sapienza," Policlinico "Umberto I," Rome, Italy.

Received for publication Feb 17, 2006; accepted for publication March 15, 2006.

Address for reprints: Erino A. Rendina, MD, Division of Thoracic Surgery, Sant'Andrea Hospital, Via di Grottarossa 1035, 00189 Roma, Italy (E-mail: erinoangelo.rendina@tin.it).

J Thorac Cardiovasc Surg 2006;132:192-4

$0022-5223 / \$ 32.00$

Copyright $\odot 2006$ by The American Association for Thoracic Surgery doi:10.1016/j.jtcvs.2006.03.021
}

eration. A right-sleeve pneumonectomy associated with resection and prosthetic reconstruction of the SVC was performed. Pathologic examination documented epithelioid leiomyosarcoma. Twenty-nine hilar and mediastinal nodes were removed. Only 3 peribronchial nodes resulted at pathologic analysis.

Case 2 was a 55-year-old woman who presented with an endoluminal tumor of the SVC with complete vascular obstruction for a longitudinal extension of approximately $7 \mathrm{~cm}$, confirming SVC syndrome. The patient underwent radical removal of the tumor by a complete resection and reconstruction of the SVC. A metastatic tumor of an unidentified origin was found at the pathologic examination.

No intraoperative or postoperative major complications occurred. Both patients are well and without evidence of disease 16 months (case 1) and 13 months (case 2) after surgery.

\section{Surgical Technique}

The surgical approach was posterolateral thoracotomy in case 1 and muscle sparing lateral thoracotomy in case 2 .

After complete isolation and distal and proximal clamping of the SVC, the caval segment infiltrated by the tumor was resected and vascular continuity was restored by interposition of a heterologous pericardial prosthetic tube. Intravenous sodium heparin $(0.5$ $\mathrm{mg} / \mathrm{kg}$ ) was administered before clamping. We previously described an original technique for the construction of a biologic conduit. ${ }^{1,2}$ The bovine pericardial leaflet is trimmed to a rectangular shape of the resected caval segment length, wrapped around a syringe to obtain the appropriate diameter, and sutured longitudinally. In our past experience, the longitudinal closure was performed with a running suture of 5-0 or 6-0 monofilament nonabsorbable material. In the present experience, we tried to optimize 


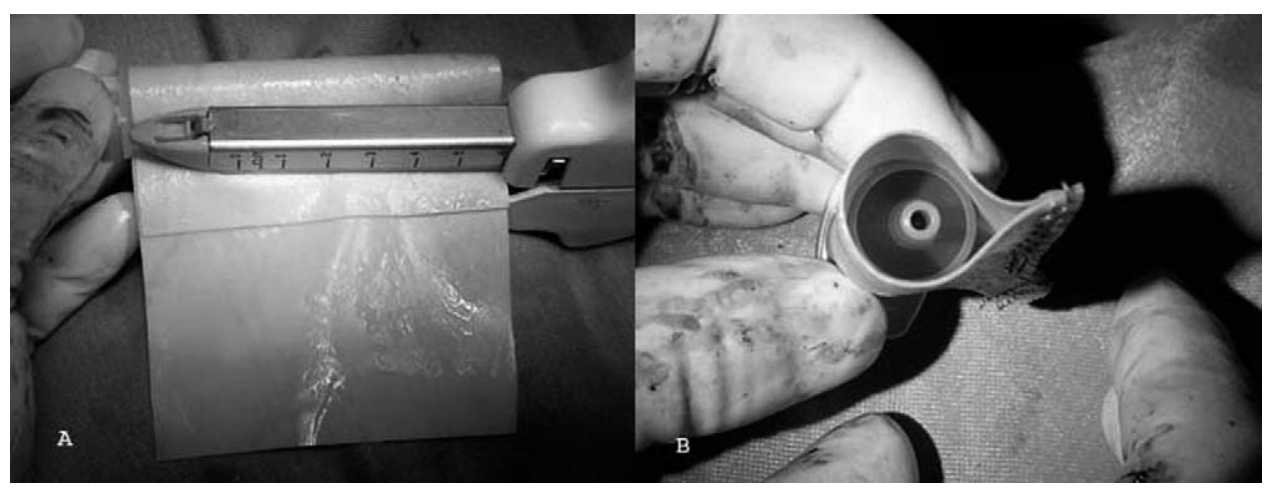

Figure 1. Construction of the pericardial tube. A, Gastrointestinal anastomosis stapler is applied to the leaflet wrapped around a 5-mL syringe. B, Construction of the tube is completed.

this technique by performing the longitudinal suture with a linear reloadable stapler (gastrointestinal anastomosis stapler with $3.8-\mathrm{mm}$ titanium staples). A 5- or 10-mL syringe (depending on the diameter of the resected vessel) was used to calibrate the graft diameter (Figure 1, $A, B$ ).

The distal anastomosis was performed first, with a 5-0 polypropylene suture, starting from the posterior aspect of the prosthesis. The proximal anastomosis was subsequently performed with the same technique. The mechanical suture line helped to keep the graft properly positioned and aligned. Low-weight heparin (100 $\mathrm{U} / \mathrm{kg} / \mathrm{d}$ ) was administered subcutaneously for 1 month after the operation.

Computed tomography images demonstrating a perfectly patent caval graft 12 months after surgery are shown for both cases in Figure 2. Figure 2, $B$ shows the suture line of the mechanical stapler of a perfectly aligned SVC graft.

\section{Discussion}

Biologic materials have achieved large acceptance in the reconstructive procedures of low-pressure thoracic great vessels after oncologic resection. ${ }^{1-5}$ In the past decade we have extensively used autologous or heterologous pericardium for both patch and prosthetic repair of the SVC and pulmonary artery. ${ }^{1-3}$ When an SVC replacement is required, bovine pericardium is preferred because the autologous tissue is not sufficient to create a long conduit. The available detoxified bovine pericardial flaps have strongly improved the graft biocompatibility providing heterologous tissue advantages comparable to those of autologous tissue. The pericardial conduit has lower risks of infection and thrombosis if compared with synthetic materials and does not require longterm anticoagulation. Moreover, bovine pericardium shows further favorable features with respect to fresh tissue. It has even and stiffer edges that make it easier to suture the graft to the vascular wall. Furthermore, bovine pericardium exhibits reduced elasticity, which makes it easier to trim the pericardial graft to the appropriate size. The technical devices described in this article (mechanical stapler) enable a quicker and easier procedure for the tube construction and confer a more regular shape to the vascular graft, so its adaptation to the caval stumps is facilitated. The use of a mechanical suture for the longitudinal closure of the graft adds safety and precision to the previously described technique and reduces the surgical time.
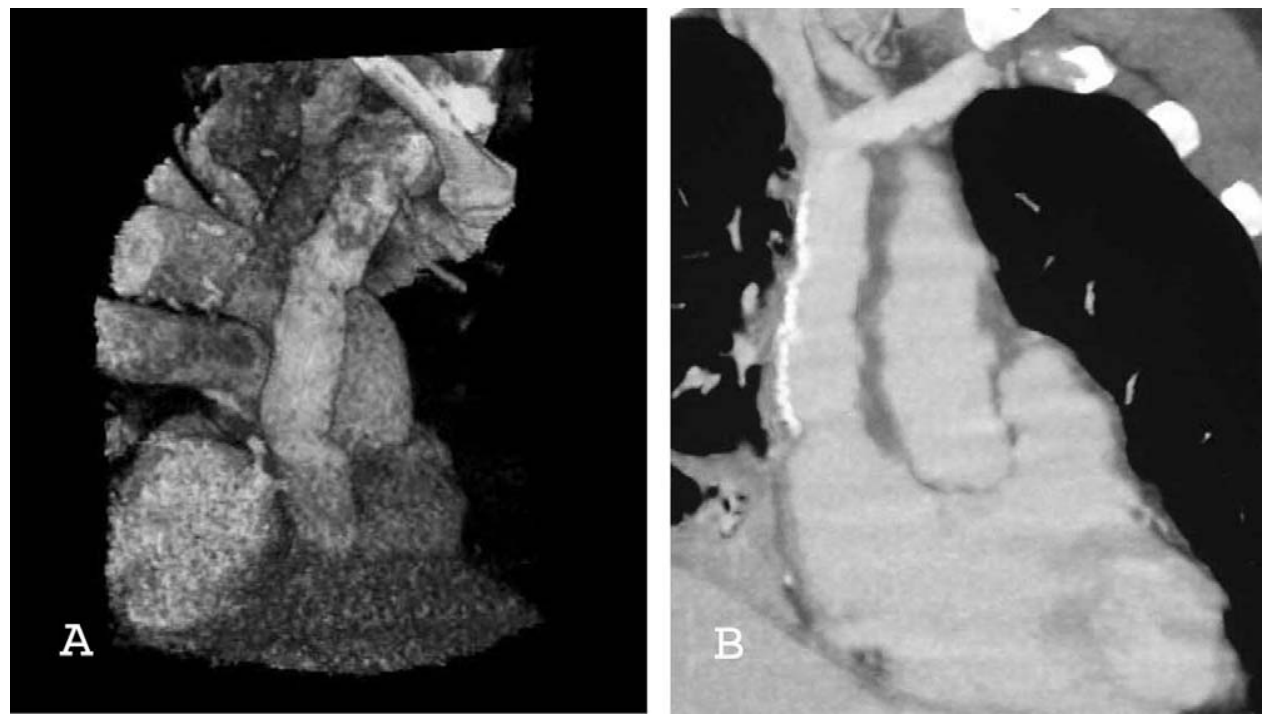

Figure 2. Postoperative computed tomography controls 12 months after surgery. A, Case 1. B, Case 2: suture line of the mechanical stapler of a perfectly aligned SVC graft is visible. 


\section{References}

1. Venuta F, Rendina EA, Coloni GF. Surgery of the superior vena cava: resection and reconstruction. CTSnet 2003. Available at: www.ctsnet. org/sections/clinicalresources/thoracic/expert_tech-6.html. Accessed 22 October 2003.

2. Rendina EA, Venuta F, De Giacomo T, Ciccone AM, Moretti M, Ruvolo G, et al. Sleeve resection and prosthetic reconstruction of the pulmonary artery for lung cancer. Ann Thorac Surg. 1999;68:9951002.
3. D'Andrilli A, Ibrahim M, Venuta F, De Giacomo T, Coloni GF, Rendina EA. Glutaraldehyde preserved autologous pericardium for patch reconstruction of the pulmonary artery and superior vena cava. Ann Thorac Surg. 2005;80:357-8.

4. Piccione W, Penfield Faber L, Warren WH. Superior vena cava reconstruction using autologous pericardium. Ann Thorac Surg. 1990;50:417-9.

5. Spaggiari L, Galetta D, Veronesi G, Leo F, Gasparri R, Petrella F, et al. Superior vena cava replacement for lung cancer using a heterologous (bovine) prosthesis: preliminary results. J Thorac Cardiovasc Surg. 2006;131:491-2.

\title{
Atriocaval laceration presenting as delayed pericardial tamponade
}

\author{
Forrest 0. Moore, MD, ${ }^{a}$ John D. Berne, MD, ${ }^{a}$ Gerard J. Fulda, MD, ${ }^{\mathrm{b}}$ Adam D. Fox, D0, \\ Glen H. Tinkoff, MD, ${ }^{\mathrm{b}}$ Allen L. Davies, MD, ${ }^{\mathrm{b}}$ and Kathleen McNicholas, MD, ${ }^{\mathrm{b}}$ Tyler, Tex \\ and Newark, Del
}

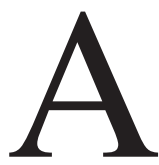
triocaval injuries are rare and usually manifest in patients presenting in extremis. Delayed complications are even more uncommon. This case documents delayed pericardial tamponade in a patient with an atriocaval laceration.

\section{Clinical Summary}

A 39-year-old man was struck in the anterior chest by a large metal beam. The patient was hemodynamically stable with a pulse rate of 106 beats/min. Chest radiograph was normal, and a focused assessment for the sonography in trauma was negative for pericardial fluid. Computed tomography scan of the chest was unremarkable.

The patient was admitted to the intensive care unit, and a transthoracic echocardiogram revealed a normal ejection fraction and no pericardial effusion. He was extubated on hospital day 2, and the chest tube was removed on hospital day 5 . He was discharged the following day. Physical examination and chest radiograph results were normal 1 week after discharge.

Two weeks later the patient presented to the cardiologist with a 2-day history of shortness of breath. A transthoracic echocardiogram demonstrated a large pericardial effusion.

From the Division of Trauma and Surgical Critical Care, East Texas Medical Center, ${ }^{a}$ Tyler, Tex, and Department of Surgery, Christiana Care Health System, ${ }^{\mathrm{b}}$ Newark, Del.

Received for publication Feb 27, 2006; accepted for publication March 15, 2006.

Address for reprints: Forrest O. Moore, MD, Division of Trauma and Surgical Critical Care, East Texas Medical Center, 1020 E. Idel, Tyler, TX 75701 (E-mail: moore677@aol.com).

J Thorac Cardiovasc Surg 2006;132:194-5

$0022-5223 / \$ 32.00$

Copyright $\odot 2006$ by The American Association for Thoracic Surgery doi:10.1016/j.jtcvs.2006.03.022
The cardiothoracic surgery department was consulted, and the patient was taken to the operating room. A median sternotomy was performed, followed by a pericardiectomy for a tense hemopericardium.

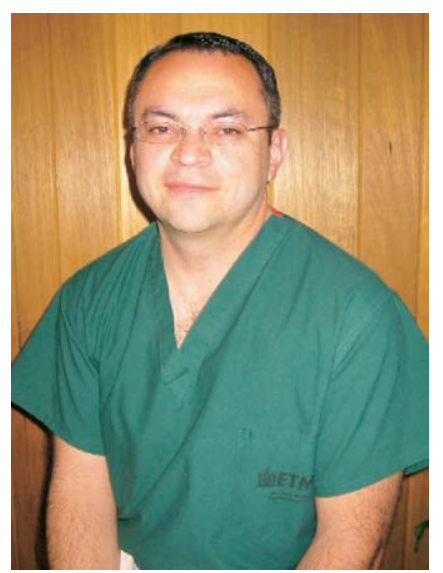

Dr Moore Further examination revealed a thrombus in the region of the inferior vena cava-atrial junction and a partial-thickness injury (Figure 1). Because of the injury location and the need for repair, the patient was placed on cardiopulmonary bypass. Multiple pledgeted sutures were used to close the partialthickness defect.

The patient's postoperative course was uncomplicated. He was extubated on postoperative day 2 , the chest tubes were removed on postoperative day 3 , and he was discharged on postoperative day 6 .

The patient was reevaluated on postoperative day 16 and was recovering uneventfully.

\section{Discussion}

Intrapericardial great vessel injury is a rare occurrence, accounting for a small fraction of the $25 \%$ of trauma deaths that are the result of thoracic injuries. ${ }^{1}$ Although the incidence of atriocaval injury is unknown, Fulda and colleagues ${ }^{2}$ reported 59 patients with ruptures of the heart and/or pericardium, 7 of whom had atriocaval junction disruption. The survival from atriocaval injuries, once routinely fatal, has been improved with rapid transport to trauma centers and rapid diagnosis. Yet, $50 \%$ of patients die before reaching the hospital, whereas $50 \%$ of the remainder die despite treatment. ${ }^{3,4}$

Most documented cases of atriocaval injury manifest immediately as hemopericardium with pericardial tamponade, if not already having proven fatal from exsanguinations caused by associated pericardial disruption or associated injuries. Differential diagnosis should include pericardial tamponade from intrapericardial great vessel injury in a patient with refractory hypotension and shock, especially without obvious blood loss. 